\title{
The interaction of homophthalic anhydride with (triphenylphosphoranylidene)acetates
}

\author{
Oleh V. Shablykin ${ }^{a^{*}}$, Daniil O. Merzhyievsky ${ }^{\mathrm{b}}$, Olga V. Shablykina ${ }^{\mathrm{b}}$ \\ ${ }^{a}$ Institute of Bioorganic Chemistry and Petrochemistry of the NAS of Ukraine, \\ Murmanska st., 1, Kyiv, 02660, Ukraine \\ ${ }^{\mathrm{b}}$ Department of Chemistry, Taras Shevchenko National University of Kyiv, \\ Volodymyrska Street, 64/13, Kyiv 01601, Ukraine \\ shablykin@gmail.com
}

Keywords: homophthalic anhydride, (triphenylphosphoranylidene)acetates, Wittig reaction, selfcondensation of homophthalic anhydride.

In the study of the interaction of homophthalic anhydride and methyl (triphenylphosphoranylidene)acetate, along with (1-oxo- $1 H$-isochromen-3-yl)acetate obtaining, two minor products - (1,3-dioxo1,2,3,4-tetrahydronaphthalene-2-yl)acetate and 2-((1-oxo- $1 H$-isochromen-3-yl)methyl)benzoic acid - had been isolated. The action of tert-butyl (triphenylphosphoranylidene)acetate on homophthalic anhydride didn't lead to Wittig reaction; the encumbered ylide demonstrated only its basicity, and products of homophthalic anhydride self-condensation - 2-((1-oxo-1H-isochromen-3-yl)methyl)benzoic acid and 12-hydroxy-5H-dibenzo[ $c, g]$ chromen-5-one - were formed.

\section{Introduction}

The interaction of (triphenylphosphoranylidene)acetates and related compounds with cyclic anhydrides is not a sufficiently understood branch of ylide chemistry [1-3]. The reaction proceeds via a ring transformation to provide lactones (Scheme 1). Interaction of (triphenylphosphoranylidene)acetates with cyclic anhydrides of aliphatic acids (substituted glutaric and succinic acids) as well as with phthalic anhydride has been investigated in detail with determination of regioselectivity and tautomerism of products and isolation of phosphonium intermediates $[2,3]$.
It was also found that action of ethyl (triphenylphosphoranylidene)acetate on nonsymmetric homophthalic anhydride (AHPA) results in formation of ethyl (isocoumarin-3-yl)acetate in good yield [2].

Esters of (isocoumarin-3-yl)acetic acid have some reactive functional groups (ester, lactone, latent carbonyl and active methylene group) which are important for isocoumarin chemistry. Therefore it makes sense to investigate reaction of AHPA with other (triphenylphosphoranylidene)acetates, for instance, methyl and tert-butyl esters. 


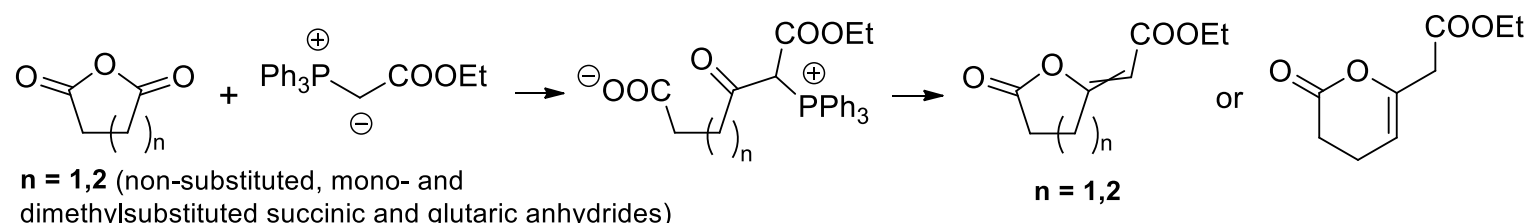

$n=1,2$ (non-substituted, mono- and
dimethylsubstituted succinic and glutaric anhydrides)
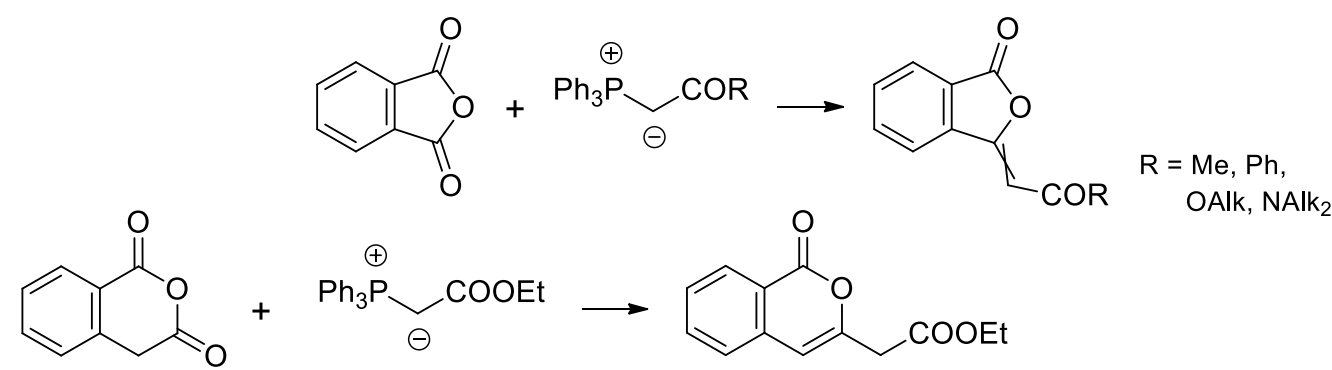

Scheme 1. The interaction of cyclic anhydrides and triphenylphosphoranylidenes with carbonyl functions (literature data).

\section{Results and discussion}

Acylation of ylide 2a with AHPA 1 was performed in Wittig reaction conditions proposed in publications $[2,4]$. However, we noted that the content of advised product 3 in reaction mixture does not exceed $60 \%$ (according to LCMS data). The column chromatography allowed isolating, along with isocoumarin 3, byproducts 4 and 5 (Scheme 2).

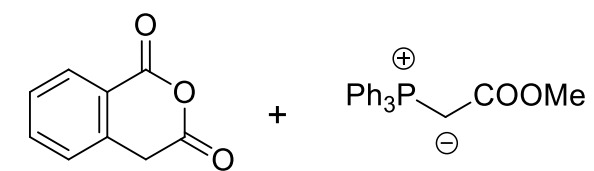

1

2a<smiles>CC(=O)Cc1cc2ccccc2c(=O)o1</smiles>

$3(60 \%)$<smiles>[13CH3][14C]([14CH3])c1cc2ccccc2c(=O)o1</smiles><smiles>CC(=O)c1c(O)cc2ccccc2c1O</smiles>

$5(10 \%)$

Scheme 2. The interaction of homophthalic anhydride with methyl (triphenylphosphoranylidene)acetate.
Acid 4 is formed by base-catalysed selfcondensation of AHPA that is well-known in AHPA chemistry [5-8]. In contrast, formation of diketone 5 was unexpected because only a few examples are known when aliphatic and aromatic carbonyl group of AHPA both attacked one molecule [9].

One would expect a high content of enol form of compound 5 and, in fact, only naphthalene-like enol structure was observed in NMR and IR spectra. Rigorous definition of signals in ${ }^{1} \mathrm{H}$ and ${ }^{13} \mathrm{C}$ NMR of compound 5 was performed using HSQC and HMBC experiments, whose data are represented in Table 1 and Figure 1. The latter serves also to illustrate the information obtaining by COSY and NOESY experiments. 
Table 1. Data of NMR spectroscopy of methyl 1,3-dihydroxynaphthalene-2 carboxylate 5

\begin{tabular}{|c|c|c|}
\hline \multirow[t]{2}{*}{${ }^{1} \mathbf{H} \mathbf{N M R}, \delta, \mathbf{p p m}$} & \multicolumn{2}{|r|}{${ }^{13} \mathrm{C}$ NMR, $\delta$, ppm } \\
\hline & HSQC & НMBC \\
\hline $4.08\left(\mathrm{~s}, 3 \mathrm{H}, \mathrm{CH}_{3}\right)$ & $53.0\left(\mathrm{CH}_{3}\right)$ & $170.4(\mathrm{C}=\mathrm{O})$ \\
\hline $6.76(\mathrm{~s}, 1 \mathrm{H}, \mathrm{H}-4)$ & $102.5(\mathrm{C}-4)$ & $\begin{array}{l}97.3(\mathrm{C}-2), 119.6(\mathrm{C}-8 \mathrm{a}), 125.9(\mathrm{C}-5), 137.9(\mathrm{C}-4 \mathrm{a}), \\
153.7(\mathrm{C}-3), 161.7(\mathrm{C}-1), 170.4(\mathrm{C}=\mathrm{O})\end{array}$ \\
\hline $7.27(\mathrm{t}, J=7.1 \mathrm{~Hz}, 1 \mathrm{H}, \mathrm{H}-7)$ & $123.1(\mathrm{C}-7)$ & 119.6 (C-8a), 125.9 (C-5), 130.6 (C-6) \\
\hline $7.49(\mathrm{t}, J=6.8 \mathrm{~Hz}, 1 \mathrm{H}, \mathrm{H}-6)$ & $130.6(\mathrm{C}-6)$ & 119.6 (C-8a), 123.1 (C-7), 124.2 (C-8), 137.9 (C-4a) \\
\hline $7.53(\mathrm{~d}, J=6.8 \mathrm{~Hz}, 1 \mathrm{H}, \mathrm{H}-5)$ & $125.9(\mathrm{C}-5)$ & 102.5 (C-4), 119.6 (C-8a), 123.1 (C-7), 137.9 (C-4a) \\
\hline $8.22(\mathrm{~d}, J=8.3 \mathrm{~Hz}, 1 \mathrm{H}, \mathrm{H}-8)$ & $124.2(\mathrm{C}-8)$ & 125.9 (C-5), 130.6 (C-6), 137.9 (C-4a), 161.7 (C-1) \\
\hline 8.90 (br. s, 1H, OH-3) & - & - \\
\hline 11.31 (br. s, $1 \mathrm{H}, \mathrm{OH}-1)$ & - & - \\
\hline
\end{tabular}

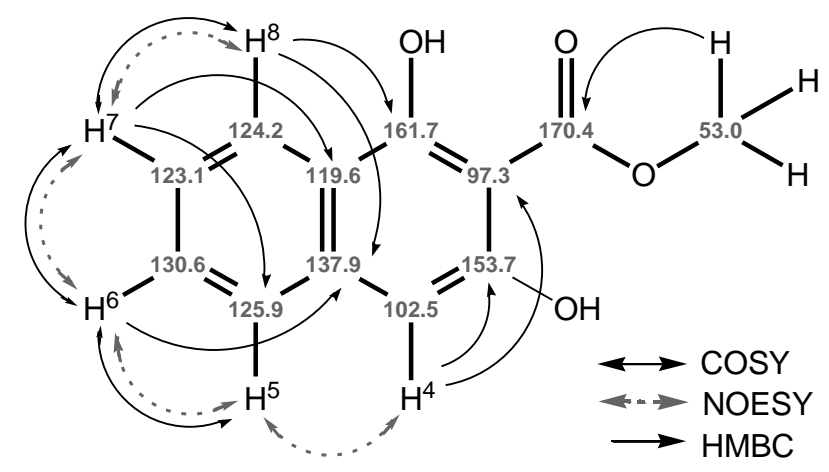

Figure 1. Data of COSY and NOESY experiments and most important HMBC of methyl 1,3-dihydroxynaphthalene2-carboxylate 5.

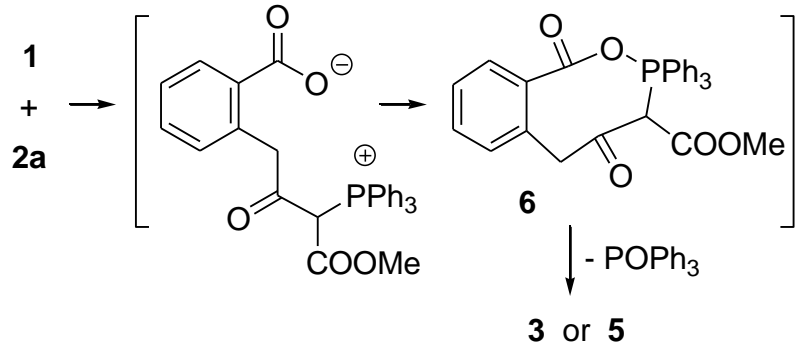

Scheme 3. The proposed mechanism for the compounds 3 and 5 formation.
By analogy with the classical Wittig reaction, it can be assumed that the ring closure of compounds $\mathbf{3}$ and $\mathbf{5}$ is preceded by the creation of an intermediate 6 with the $\mathrm{P}-\mathrm{O}$ bond (Scheme 3). In this case, the consequence of the molecule $\mathrm{POPh}_{3}$ cleavage can be the formation of $\mathrm{C}-\mathrm{O}$ bond (isocoumarin 3 ) or $\mathrm{C}-\mathrm{C}$ bond (naphthalene 5). 


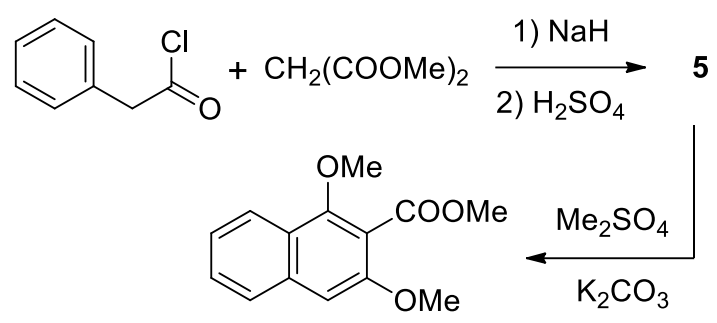

(60\% over 3 steps)

Scheme 4. Alternative preparative synthesis of diphenol 5 (literature data).

It is interesting that an alternative way of the aromatic system $\mathbf{5}$ formation was proposed earlier in Ref. [10] (Scheme 4); although diphenol $\mathbf{5}$ itself wasn't isolated in its pure form, but was converted to dimethyl ether.

The involving of tert-butyl ester $\mathbf{2 b}$ instead of $\mathbf{2 a}$ shows how the Wittig reaction of AHPA is sensitive to steric effects. In this case, analogous of products $\mathbf{3 , 5}$ were not detected in a reaction mixture but acid 4 was the main product (Scheme 5). A small amount of dibenzocoumarin 7 was also isolated. Product 7 is formed by intramolecular acylation of compound 4 [11] and was obtained earlier by acid-catalysed condensation of homophthalic acid [12].

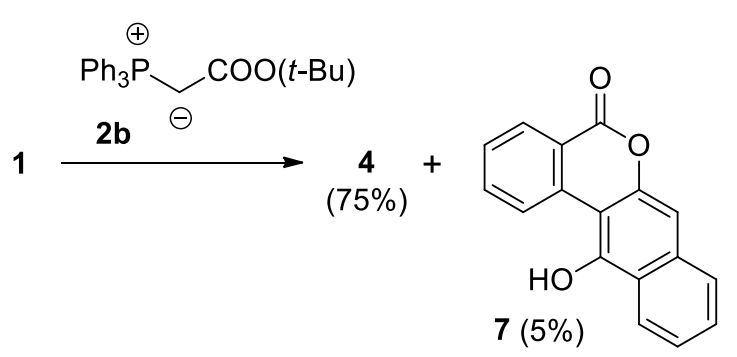

Scheme 5. The action of tert-butyl (triphenylphosphoranylidene)acetate on homophthalic anhydride.

\section{Experimental part}

All reagents and solvents were purchased from Aldrich and used as received.

Melting points were determined using a Fisher-Johns melting point apparatus and uncorrected.

${ }^{1} \mathrm{H},{ }^{13} \mathrm{C}$ NMR spectra were recorded at Varian Unityplus 400 spectrometer operating at $400 \mathrm{MHz}$ frequency for ${ }^{1} \mathrm{H}$ and $100 \mathrm{MHz}$ for ${ }^{13} \mathrm{C}$ experiments. NMR chemical shifs are reported in $\mathrm{ppm}$, in the $\delta$ scale and are referenced using TMS as internal standard.

LC-MS data were acquired on Agilent 1100 HPLC system equipped with diode matrix and Agilent LC/MSD SL mass-selective detector, column: Zorbax SB-C18, $1.8 \mu \mathrm{m}$, $4.6 \times 150 \mathrm{~mm}$. Eluent: A) 95:5 $\mathrm{MeCN}-\mathrm{H}_{2} \mathrm{O}$, $0.1 \% \quad \mathrm{CF}_{3} \mathrm{CO}_{2} \mathrm{H}$, and $\left.\mathrm{B}\right) \quad 0.1 \%$ aqueous $\mathrm{CF}_{3} \mathrm{CO}_{2} \mathrm{H}$; the eluent flow rate was $3 \mathrm{ml} / \mathrm{min}$. The injection volume was $1 \mu$ l. The UV detectors recorded at 215, 254, and $285 \mathrm{~nm}$.

IR spectra were recorded on a Vertex 70 spectrometer in $\mathrm{KBr}$ pellets.

\section{General procedure for reaction of} HPA 1 and ylides 2. A solution of homophthalic anhydride 1 (1.5 g) and the ylide $2(3.22 \mathrm{~g})$ in chloroform $(30 \mathrm{ml})$ was refluxed under argon for $48 \mathrm{~h}$. After solvent evaporating solid residue was separated by silica gel column chromatography (Merck Grade 9385, $60 \AA$, 230-400 mesh) eluted with a dichloromethane-hexane $\quad(1: 1-1: 0)$ gradient solvent system; and the fractions were 
monitored by TCL (on plates Silufol UV-254 using a system 9:1 chloroform-methanol as the eluent with UV light visualization). It was given three fractions (when ylide $\mathbf{2 a}$ was used) and two fractions (after ylide $\mathbf{2 b}$ using).

The physical characteristic and spectral data of known compounds should be seen in Ref. [5-8] for 2-[(1-oxo- $1 H$-isochromen-3-yl)methyl]benzoic acid 4 and in Ref. [11, 12] for 12-hydroxy-5H-dibenzo[ $[c, g]$ chromen-5-one 6.

Methyl 2-(1-oxo-1H-isochromen-3-yl)acetate 3. M.p. $125-126^{\circ} \mathrm{C}$. IR $\left(\mathrm{KBr}, v, \mathrm{~cm}^{-1}\right)$ : 3087, 3034, 2964, 2931, 1722, 1663, 1605, 1568, 1483, 1440, 1367, 1325, 1270, 1214, 1161, 1051, 1024, 1005, 978, 846, 734, 688. ${ }^{1} \mathrm{H}$ NMR (DMSO-d $)$ ): 3.67 (s, 3H, COOMe), 3.71 (s, 2H, $\mathrm{CH}_{2}$ ), 6.74 (s, 1H, H-4), 7.55-7.61 (m, 2H, H-5,7), 7.82 (t, J=7.3 Hz, 1H, H-6), $8.11(\mathrm{~d}, \quad J=7.7 \mathrm{~Hz}, \quad 1 \mathrm{H}, \quad \mathrm{H}-8) . \quad{ }^{13} \mathrm{C} \mathrm{NMR}$ (DMSO- $\mathrm{d}_{6}$ ): 38.9, 52.7, 106.3, 120.0, 126.4, 129.1, 129.3, 135.9, 137.2, 151.0, 162.0, 169.5. LC MS (APCI): $m / z=219.1[\mathrm{M}+1]^{+}$.

Methyl 1,3-dihydroxynaphthalene2-carboxylate 5. M.p. $118-119{ }^{\circ} \mathrm{C}$. IR (KBr, v, $\left.\mathrm{cm}^{-1}\right)$ : 3445, 1643, 1569, 1498, 1455, 1433, 1401, 1329, 1248, 1136, 1077, 964, 866, 830, 652, 627. LC MS (APCI): $m / z=217.1[\mathrm{M}-1]^{-}$.

\section{Conclusions}

Hereby it was shown that throughout interaction of homophthalic anhydride and methyl (triphenylphosphoranylidene)acetate the product of Wittig reaction - methyl (1-oxo$1 H$-isochromen-3-yl)acetate - can be produced indeed; but it's impossible to implement analogues reaction with tert-butyl (triphenylphosphoranylidene)acetate because of domination of homophthalic anhydride selfcondensation in this case.

\section{Acknowledgements}

The authors thank Mr. Vitaliy V. Polovinko (Enamine Ltd.) for NMR measurements.

Publications are based on the research provided by the grant support of the State Fund For Fundamental Research (project N 33373).

\section{References}

[1] Kolodiazhnyi OI. Phosphorus Ylides: Chemistry and Applications in Organic Synthesis: WILEY-VCH; 1999, pp. 380-382.

[2] Abell AD, Doyle IR, MassyWestropp RA. The Wittig Reaction with Glutaric and Succinic Anhydrides. Aust. J. Chem. 1982; 35: 22772287.

[3] Kayser MM, Hatt KL, Hooper DL. Mechanism of Wittig reaction with cyclic anhydrides. Can. J. Chem. 1992; 70: 1985-1996.

[4] Abell AD, Massy-Westropp RA. Aspects of the mechanism of the Wittig reaction between cyclic anhydrides and stabilized phosphoranes. Aust. J. Chem. 1982; 35: 2077-2087.

[5] Aknin J, Molho D. Synthèse de la (carboxy-2' benzyl)-3 isocoumarine et de la spiro-3,3' phtalide dihydro isocoumarine. Bull. Soc. Chim. France, 1965; (10): 3021-3024.

[6] Bogdanov MG, Mitrev Y, Tiritiris I. New Highly Diastereoselective Perkin/Michael Addition Domino Reaction between Homophthalic Anhydride and Aromatic Aldehydes: A Facile Approach to Blue- 
Fluorescent Dibenzo $[c, h]$ chromenones. Eur. J. Org.

Chem. 2011; 2011(2): 377-384.

[7] Ishchenko VV, Voevoda NM, Shablykina OV, Turov OV, Khilya VP. Reduction of 3-(carboxyaryl)isocoumarins with sodium borohydride. Chem. Het. Comp. 2012; 47(10): 1212-1224.

[8] Jagtap PG, Baloglu E, Southan G, Williams W, Roy A, Nivorozhkin A, Landrau N, Desisto K, Salzman A, Szabo C. Facile and Convenient Syntheses of 6,11-dihydro-5H-indeno[1,2-c]isoquinolin- 5-ones and 6,11-dihydro-5H-indolo[3,2-c]isoquinolin-5-one. Org. Lett. 2005; 7(9): 1753-1756.

[9] Sorrie AJS, Thomson RH. Hydroxybenzotropones. Part III. Synthesis of a hydroxydimethoxydibenzotropone. J. Chem. Soc. 1955; 2244-2247.

[10] Brockway AJ, González-López M, Fettinger JC, Shaw JT. Direct Displacement of Alkoxy Groups of Vinylogous Esters by Grignard Reagents. J. Org. Chem. 2011; 76(9): 3515-3518.

[11] Shablykina O, Ishchenko V, Chumachenko S, Khilya V. Intramolecular cyclization of 3-(2-carboxyphenyl)- and 3-(2-carboxybenzyl)isocoumarine. Taras Shevchenko Nat. Univ. Kyiv: Chem. Bull. 2013; 49(1): 64-66 (in Ukrainian).

[12] Belgaonkar VH, Usgaonkar RN. Isocoumarins. Part XIV. Synthesis of 3-Benzylisocoumarins and 3-Benzyl-1(2H)isoquinolones. Indian J. Chem. 1975; 13: 336-338. 